\title{
As Noçóes de Stimmung em uma Série Histórica: eNTre DisposiçÃo e AtMosfera ${ }^{1}$
}

\author{
Arlenice Almeida da Silva ${ }^{2}$
}

\begin{abstract}
RESUMO: A relação entre arte e filosofia é examinada com base na noção de Stimmung, que surge no século XVIII, na teoria musical, como relação de proporção entre tons ou instrumentos, sendo, em seguida, transposta para a estética, no final do século, com Kant e Fichte. Em Kant, a Stimmung refere-se à disposiçáo das faculdades de conhecimento para um conhecimento em geral, isto é, como o pressuposto da apresentação estética, por meio da qual se preserva a noção de proporçâo entre as faculdades. Em Sobre o espirito e a letra na filosofia, Fichte assinala que a disposiçáo estética é o modo de atuar do impulso estético, ligado livremente e diretamente à faculdade da imaginação e à atividade de criação. Essa tradição estética é revista pelo historiador Aloös Riegl, em 1899, no ensaio intitulado Die Stimmung als Inhalt der moderne Kunst, no qual o conceito de Stimmung é pela primeira vez apresentado em chave histórica, enquanto conteúdo da arte moderna, no sentido de atmosfera, isto é, da vivência de uma relaçáo por meio da qual a consciência, em conformidade com a lei imanente, adquire alguma certeza. Revisão semelhante foi realizada pelo jovem filósofo György Lukács, em $A$ alma e as formas, de 1910, na qual o autor pensa as diferenças de sentido entre as noçóes de Stimmung e de atmosfera (Atmosphäre).
\end{abstract}

PALAVRAS-CHAVE: Stimmung. Fichte. Kant. Riegl. Lukács.

Constata-se, com um misto de curiosidade e espanto, que a noção de Stimmung continua muito utilizada até hoje, na estética e na crítica de arte. Nesse sentido, o artigo que se segue visa à interpretação desse fenômeno contemporâneo, por meio de uma reflexão histórica que recua no tempo para articular, assim, significados e usos de dois momentos diferentes: do final do século XVIII, quando o termo surge na estética filosófica e um século depois, já no final do século XIX e começo do XX, quando são propostos outros significados, seja na história da arte de Aloïs Riegl, seja na estética do jovem György Lukács. Com efeito, não se trata aqui de atribuir a essas manifestaçôes

\footnotetext{
${ }^{1}$ http://dx.doi.org/10.1590/S0101-31732016000500005

${ }^{2}$ Professora de Estética e Filosofia da Arte do Departamento de Filosofia da UNIFESP. Autora do livro As guerras da independência e de artigos sobre a estética do jovem György Lukács. É membro do corpo editorial das revistas Fronteiraz, Limiar, Kinesis, Ipseitas e Miscelânea; membro da Associaçáo Brasileira de Estudos do Século XVIII (ABES-18), pesquisando atualmente as relações entre Filosofia e Literatura no século XVIII. arlenice@uol.com.br
} 
históricas uma evolução necessária, concedendo-lhe uma teleologia específica, mas tão somente de localizar uma série histórica, haja vista que outras são possíveis, como bem demonstrou Caroline Welsh, em recente artigo de 2009, ou mesmo Hans Ulrich Gumbrecht, em 2014. Espera-se, assim, corroborar para as múltiplas possibilidades de compreensão do conceito e, quando for o caso, contribuir para dissipar alguns problemas de tradução.

De fato, trata-se de um termo polissêmico, com muitas camadas semânticas e históricas e, portanto, de difícil tradução. Sobre isso, basta mencionar o monumental estudo de estilística literária de Leo Spitzer, Ideias clássicas e cristãs de Harmonia do mundo (Classical and Christian Ideas of Harmony), de 1963, no qual a noção de Stimmung deriva das ideias de harmonia do mundo, que Spitzer examina desde os Pitagóricos até Novalis, demorando-se especialmente nos autores medievais. Para o nosso propósito, visamos a uma série histórica da noção de Stimmung, em língua alemã, na qual convergem vários sentidos: etimologicamente, a palavra deriva de Stimme, voz, mas também de $M u t$, coragem ou brio, e de Gemüt, índole ou ânimo; daí sua tradução mais frequente como sentimento ou disposição subjetiva. Contudo, o termo pode referir-se a uma relação percebida, isto é, a algo externo ou objetivo, como uma obra de arte ou a própria natureza e, nesse sentido, o termo é vertido como atmosfera ou circunscriçáo de um campo de visáo. No começo do XVIII, como demonstra David Wellbery, o termo Stimmug, nutrindo ainda uma forte conexão com essa tradição antiga e medieval, apontada por Spitzer, ressurge, referindo-se à teoria musical, no sentido mais preciso de temperare, ou seja, como consonância ou concórdia, além de ter o sentido de afinação ou sintonizaçáo dos instrumentos, por meio do qual era possível pensar em relaçóes de proporção entre tons e instrumentos, visando a uma noção da harmonia musical (WELLBERY, 2003, p. 704-733).

\section{I}

No final do século XVIII, o termo foi transposto para a estética filosófica, ganhando uma conotação especulativa. A passagem decisiva se dá com Kant, na Crítica do Juízo, quando o termo é deslocado de seu sentido musical e dessa relação prática entre instrumentos ou tons, para transpor-se para o campo das faculdades, como pressuposto da apresentação estética, preservando, no entanto, a noção de proporção. A Stimmung adquire, então, o sentido de disposição, ou seja, de uma proporção entre as faculdades: precisamente, afirma Kant: "[...] o estado de ânimo (Gemutszustand), isto é, a disposição 
(Stimmung) das faculdades de conhecimento para um conhecimento em geral.” (KANT, 1993, \$21, p.84). Ora, sabemos que a disposição estética é específica e, nesse caso, ela é determinada apenas pelo sentimento (Gefühl) e não por conceitos; sobretudo, que nela se dá uma concordância recíproca, o conhecido jogo recíproco entre as faculdades do conhecimento, o que garante a comunicação e a validade geral do ajuizamento estético. Assim, é essa função de comunicação que encontramos, por exemplo, na Analítica do belo, no $\mathbb{S}$ 9, na indagaçáo de Kant sobre se, no juízo de gosto, o sentimento de prazer precede o ajuizamento do objeto ou se esse ajuizamento precede o prazer. A resposta de Kant é clara, mas não óbvia: mesmo advertindo que se trata da comunicação de uma unidade ou relação (Verhältnis) que é subjetiva e só pode ser conhecida por meio da sensação, para Kant, é a capacidade de comunicação (Mitteilungsfähigkeit) do estado de ânimo, independentemente de conceitos, que vem primeiro e depois o prazer. Portanto, a Stimmung é a disposição que, a despeito da comunicação e da validade geral, é vivida como sensação privada. Precisamente, na terceira Crítica, a função da Stimmung é a de ser meio para um ajuizamento, de validade geral, que pode ser comunicado, mas da qual nenhum conceito pode ser pensado. Nas palavras de Kant (1993, \$9, p. 64):

[...] uma representação, que como singular e sem comparação com outras todavia possui uma concordância (Zusammenstimmung) com as condiçóes da universalidade, a qual constitui a tarefa do entendimento em geral, conduz as faculdades do conhecimento à proporcionada disposição (proportionierte Stimmung), que exigimos para todo o conhecimento e que por isso também consideramos válida para qualquer um que esteja destinado a julgar através de entendimento e sentidos coligados (para todo homem).

Ressalto, assim, como complemento da comunicabilidade do estado de ânimo, a noção de proporção presente no jogo entre as faculdades da imaginaçáo e do entendimento; uma relaçáo que deriva, de um lado, da ideia antiga de temperare, no sentido analisado por Spitzer, e, do outro, do sentido musical de afinação, o qual pressupóe uma mistura proporcionada entre as faculdades, na medida em que elas são vivificadas em uma concordância recíproca (Zusammenstimmung) com as condiçôes de universalidade. Por fim, nunca é demais lembrar que, em Kant, essa concordância entre as faculdades é subjetiva, sem deixar de ser, no entanto, uma disposição interna diante de algo dado na representação, ou seja, diante da experiência. Assinalo, nessa direção, que no $\$ 51$, no tópico intitulado "Da divisão das belas artes", Kant (1993, p.169) define a música como a arte do 
[...] belo jogo das sensaçôes (as quais são geradas externamente e o qual contudo tem de poder comunicar-se universalmente) não pode concernir senão à proporção dos diversos graus da disposição (grade der Stimmung) do sentido ao qual a sensaçấo pertence, isto é, ao seu som.

Em Jena, alguns anos depois, Fichte continua a operar com a noção de Stimmung, prolongando e ampliando o sentido de disposição estética; algo muda, no entanto, em relaçáo a Kant, o que pode ser verificado na obra Sobre o espirito e a letra na filosofia, de 1795. Nesse conjunto de cartas e preleçóes, Fichte investiga uma possível aproximação entre filosofia e arte, fundamentando o impulso estético e a atividade do gênio na disposição estética (ästhetischen Stimmung). Todavia, sustenta que a disposição estética é o modo de atuar do impulso estético que, não obstante, é ligado livremente e diretamente à faculdade da imaginação e à sua atividade de criação. Ou seja, o prazer estético não se origina, como em Kant, do jogo harmônico, entre imaginação e entendimento: em Fichte, diferentemente, o prazer reside na disposição do espírito, que é aqui nomeada de esforço (Streben) da alma para se realizar com liberdade.

Por essa razão, Wellbery (2003, p. 713) denomina, com muito acerto, a Stimmung estética em Fichte de "interioridade radical", uma vez que não se trata mais de uma relação de proporção entre as faculdades, mas do "direcionamento do impulso estético", o qual realiza na obra aquilo que é desejado pelo gênio; essa disposição não consciente e que, por isso mesmo, permanece oculta, é associada ao rouxinol que "[...] sem consciência de si, impulsiona a direção de seu espírito para cima e para baixo, por toda a escala de sons e, através dos acordes diversos, desenvolve o todo de sua capacidade."(FICHTE, 2014, p.131). Com isso, temos o Eu, ou espírito, do verdadeiro gênio, se desenvolvendo sem limites, para a satisfação do impulso estético. Não se trata mais da conciliação entre as faculdades, em vista do conhecimento em geral, mas de uma ruptura que, na imagem criada por Fichte, é a encruzilhada na qual o poeta, guiado pelo impulso estético, se separa dos demais que caminham na rota da representaçáo, seguindo uma marcha independente, não mais orientada pela experiência: "Dessa contemplação que progride pelo fio da realidade, mas onde já não nos interessam mais as qualidades reais das coisas, e sim sua concordância com o nosso espírito, a imaginação educada tendo em vista a liberdade, logo se eleva à liberdade total."(FICHTE, 2014, p.142). 
Pode-se compreender, grosso modo, a Stimmung dita romântica como essa unidade criada pelo gênio, que é a manifestação da força do todo, ou unidade absoluta do $\mathrm{Eu}$, ou, ainda, que é a sensação de unidade e harmonia que tudo abarca.

O espírito deixa para trás os limites da realidade e em sua esfera própria não há limite. $\mathrm{O}$ impulso ao qual o espírito se entrega vai ao infinito. Mediante esse impulso o espírito é conduzido de um horizonte a outro e quando alcança a meta que tinha diante de si abrem-se para ele novos campos. No puro e límpido éter de sua terra natal há apenas as vibraçóes que ele próprio produz com suas asas. (FICHTE, 2014, p.143).

Em Fichte, portanto, a disposição estética é a subjetividade criadora e autônoma do artista, interioridade radical, uma qualidade do Eu que é comunicada por meio da arte.

Com efeito, se, em Kant, a possibilidade da comunicação decorria da proporção efetuada entre as faculdades, em Fichte, ao contrário, a Stimmung comunicada decorre de uma desproporção. Haja vista que a Stimmung não está na obra, mas na própria forma do movimento da subjetividade do artista que se realiza como autonomia, cuja comunicabilidade é possível pelo espírito e não pela letra da obra. Nesse sentido, diferenciando espírito e letra, Stimmung e Gestalt, ou, ainda, o que não pode ser descrito mas pode ser comunicado - o entusiasmo originário do gênio - e o que pode ser descrito e não comunicado - as formas contingentes -, Fichte, na Terceira Carta, explicita nestes termos a peculiaridade da comunicabilidade da Stimmung:

$\mathrm{O}$ artista entusiasmado expressa desse modo seu estado de ânimo (die Stimmung seiner Gemüthes) em um corpo móvel e o movimento, o curso e o fluxo de suas formas são expressão das vibrações internas de sua alma. Esse movimento deve produzir em nós a mesma disposição (Stimmung) de ânimo que havia nele; pois o artista doa sua alma à massa inerte, de modo que esta possa transferi-la a nós. Nosso espírito é a meta última de sua arte e aquelas formas são as figuras mediadoras entre ele e nós, como o ar entre nossos ouvidos e a corda. (FICHTE, 2014, p.151-153).

Assim, páginas adiante, Fichte confirma que, na obra de arte, é a “[...] unidade da disposição espiritual que domina e que deve ser comunicada ao ânimo do leitor, essa unidade é a alma da obra." (FICHTE, 2014, p.163). 
É por essa razão que Caroline Welsh, no artigo acima mencionado, vê a persistência em Fichte do esquema dualista que separa o impulso (Trieb) da representação (Vorstellung) (WELSH, 2009, p.131). Giorgia Cecchinato sustenta, na mesma direção, que Fichte, na Segunda Carta, caracteriza o impulso estético como aquele impulso que é posterior à representação (Vorstellung), o qual não se refere a um objeto, na medida em que cria para si uma finalidade, pois seu objeto é, diz Fichte, “[...] ele próprio apenas uma representação." (FICHTE, 2014, p. 129)3. Com isso, temos que, em Fichte, o impulso estético está associado à transmissáo de um sentimento ou prazer inesperado e inteiramente surpreendente, que, como em Kant, só pode ser determinado por meio da sua satisfação ou da insatisfação, visto que só por meio do prazer ele se torna consciente. Em suas palavras: “[...] o que está em nós por meio do impulso estético, descobre-se por meio de uma satisfaçáo ou insatisfação inteiramente surpreendente, sem nenhuma ligação compreensível com as demais operaçóes de nossa alma e carente de finalidade e intençấo." (FICHTE, 2014, p.129). Por outro lado, como defende Cecchinato, náo se pode esquecer que, em Kant, o prazer é a manifestação de uma concordância ou harmonia entre as faculdades de conhecimento. De todo modo, se Fichte se refere ao impulso estético, ressaltando-lhe o olho espiritual e a calma contemplação, é para advertir, na sequência, que o sentido estético só se desenvolverá depois de "[...] apaziguado o afă do saber, e satisfeito o impulso de conhecimento." (FICHTE, 2014, p. 142).

Em Fichte, portanto, vê-se que o uso da noção de disposição não se reporta à de proporção, contudo, ao movimento de direcionamento do espírito, pois, se o gênio é um protegido da natureza, é porque ele transmite, como espírito que é, imediatamente, sua Stimmung em uma matéria. A genialidade, no entanto, não deve ser confundida com a capacidade de modelar a matéria, chamada por Fichte de "agilidade da arte mecânica", porque a disposiçáo (Stimmung) interna do artista é o espírito de seu produto, e as formas contingentes nas quais ela se exterioriza são tão somente o corpo ou a letra de sua obra. Por essa razão, através da Stimmung, o gênio transportanos a outro mundo, no sentido de que, curiosamente, está bem próximo do Sublime de Schiller; em ambos, como sabemos, o gênio é autoatividade, porque é o espírito que se eleva acima do mundo sensível, ou concerne ao mundo sensível, por meio de um contato que é "[...] absolutamente invisível para nós": "[...] o gênio veste os corpos sólidos com as formas que se desvelaram ao seu olho espiritual e assim as apresenta aos seus contemporâneos." (FICHTE, 2014, p. 149).

${ }^{3}$ Cf. CECCHINATO, Giorgia. Fichte und das Problem einer Ästhetik. Würzburg: Ergon, 2009. p.99-101. 


\section{II}

Um século depois, nota-se uma mudança semântica importante, na noção de Stimmung, que coincide com o refluxo do romantismo e o fortalecimento da arte moderna. Para essa reconfiguração, a referência decisiva é certamente a de Aloïs Riegl (1858-1905), historiador da arte austríaco da chamada Escola de Viena e diretor do importante Museu de Artes Decorativas de Viena. Como profundo conhecedor das obras de arte, tornara-se uma referência na área, sobretudo após a publicação, em 1893, das Stilfragen, nas quais investiga os motivos ornamentais nas artes plásticas, especificamente vegetais, desde o Egito antigo (RIEGL, 2002). A partir de 1897, contudo, verifica-se uma virada teórica na produção intelectual de Riegl, que se reorienta agora para a investigação das bases teóricas de sua prática histórica e para a possibilidade de operar com um particular conceito de evolução, da qual resulta o esboço de uma história da arte inserida no plano de uma história universal - uma Entwicklungsgeschichte - que combina de modo original elementos da filosofia da natureza de Schelling com a estética de Herbart e a filosofia de Schopenhauer ${ }^{4}$. Nesse contexto de virada teórica, Riegl publica, em 1899, o ensaio intitulado Die Stimmung als Inhalt der moderne Kunst (A Stimmung como o conteúdo da arte moderna), exibindo de uma maneira inesperada e desconcertante outro significado para o termo (RIEGL, 1899). Nesse ponto, nós nos perguntamos: como traduzir a noção de Stimmung em Riegl, como proporção entre as faculdades, como Kant, ou como disposição subjetiva, como em Fichte?

Em primeiro lugar, cabe observar que, em Riegl, a Stimmung surge paralelamente ao conceito de Kunstwollen, um vocábulo utilizado no sentido do querer artístico ou aspiração instintiva à criação artística, que, de algum modo, poderia assemelhar-se ao conceito de impulso de Fichte ou, ainda, ao de pulsão, no sentido de Freud, pois nunca é demais relembrar que estamos na Viena do fim do século XIX. O Kunstwollen, no entanto, está em Riegl diretamente ligado à natureza e não estritamente referido à subjetividade; mesmo quando o homem, ao se julgar superior, busca corrigir e melhorar a natureza, ele forma suas obras competindo com ela, isto é, obedecendo às mesmas leis formais da natureza; nesse sentido, ele é igualmente natureza. É por essa razão que cada povo tem, para Riegl historicista, ${ }^{5}$ um Kunstwollen que os grandes artistas em determinada época concretizam, nas suas obras. Em torno desse conceito, Riegl, após sucessivas correçôes, publica, em 1897, o ensaio intitulado "A

\footnotetext{
${ }^{4}$ Cf. Swoboda e Pächt (PÄCHT, 2015, p.28)

${ }^{5}$ No prefácio para a Stilfragen, Hubert Damisch observa que, de fato, em Riegl, há uma história da arte; contudo, assevera ele: "[...] a arte não é um objeto histórico como os outros, ao fazer sua história, supõe-se que lhe damos outro sentido, aquele que o objeto sugere, e que se impóe.” (DAMISCH, 2002, p. 19).
} 
história da arte como história universal” (Kunstgeschichte als Geistesgeschichte) e o ensaio sobre a arte moderna que mencionamos acima. Neste último, Riegl esboça uma história da arte, dividida em quatro períodos, definidos em termos de representação das concepçôes do homem de sua relação com a natureza. Resumimos, para o nosso propósito, as quatro fases (Stadium): a primeira fase é a da arte primitiva, cujo poder é inerente à natureza, e cujas manifestaçóes artísticas ganham forma em objetos como os totens e fetiches, considerados suportes de harmonia. A segunda fase é a da antiguidade, com o domínio dos deuses fortes e belos, cuja meta é promover o triunfo da força física e, no plano artístico, representar a harmonia como superioridade física. $\mathrm{Na}$ terceira, a da Idade Média cristá, a harmonia é representada na força moral de um único deus, que é puro espírito. E no quarto período, o da arte moderna, Riegl vê o domínio das ciências da natureza: a separação do conhecimento da fé, por meio da qual a arte rivaliza com a natureza, que é, agora, percebida a partir do conhecimento das leis físicas que a regem. A natureza surge, no entanto, efêmera e imperfeita, como matéria perecível e em estado bruto; nessa fase, o conteúdo da arte é a Stimmung; em suas palavras "A convicção tranquila no predomínio imutável das leis da causalidade.” (RIEGL, 1899, p. 6).

De fato, vê-se que não estamos diante dos arroubos românticos da radical interioridade de Fichte, nem de um pensamento que opera exatamente nos termos do juízo de gosto kantiano, todavia, de uma sutil transposição do sentido clássico de harmonia do mundo para a arte moderna. Precisamente, com Riegl, o conceito de Stimmung recebe pela primeira vez uma abordagem histórica, na medida em que ele não é mais atemporal ou abstrato, mas o conteúdo específico da arte moderna, isto é, da produção artística desde a Renascença. De um lado, a produção moderna, para Riegl, é definida, a exemplo das fases anteriores, como a representação da relação do homem com a natureza; de outro lado, no entanto, a natureza na modernidade é multifacetada e marcada pela abundância material. Com efeito, em Riegl, a modernidade é, ao mesmo tempo, multiplicidade e caos: presença pesada e asfixiante, domínio do presente e das estreitas engrenagens do mundo e luta pela sobrevivência. Positivamente, ela é o domínio da ciência, o declínio da crença e a diminuição da violência; negativamente, nela se evidencia a seguinte tensão:

[...] os saberes descobertos são para nós frequentemente penosos, eles nos invadem o pensamento e o pessimismo é, não por acaso, um aspecto que caracteriza nossa moderna vida espiritual [...] mas esse mesmo saber desperta em nós a libertadora harmonia, quando acima da estreiteza das manifestaçóes individuais rebeldes, deixamos alcançar com a vista um elo da corrente; 
quanto mais abarcamos num único olhar esse elo, tanto mais certa, libertadora e elevada é para nós a convicção de uma ordem, na qual a harmonia equilibrase. A arte da Stimmung, isto é, a arte moderna baseia-se nessa harmonia simultaneamente posta em cena e provocada pelo saber. (RIEGL, 1899, p. 5).

Curiosamente, aqui a arte muda para não romper com a tradição e continuar sendo arte, realizando, assim, sua função geral que é a de criar forma. Se a Stimmung é, para Riegl, o conteúdo da arte moderna, é precisamente porque, nesse caso, ela é a vivência (Erlebnis) de uma relação formal, por meio da qual a consciência, em conformidade com a lei imanente, adquire alguma certeza. Náo se trata da certeza interior, mas daquilo que Wellbery nomeia "de experiência da paisagem" (Erfahrung der Lanschaft) ${ }^{6}$ e que é definido por Riegl nos seguintes termos:

Aquilo que só anseiam as almas dos homens modernos, consciente ou inconscientemente, e que se realiza no solitário estremecimento no alto de uma montanha. Não é a paz dos átrios das igrejas, mas aquilo que a visão circunscreve e que brota das múltiplas dobras da vida; é o que aparece calmamente à distância, mas ainda assim próximo da impiedosa luta, ou seja, como concórdia e harmonia, uma ao lado da outra. Sente-se ali, liberto e aliviado da pressão da vida, que jamais recua. Ele pressente que sob as oposiçóes nas quais ele simula um sentido parcial de proximidade, um inconcebível mundo espiritual, que consome todas as coisas, unifica-se de um só golpe em completa harmonia. Esse pressentimento da ordem e legalidade sobre o caos, de harmonia sobre a dissonância, de calma sobre a agitação nós chamamos de Stimmung. Seus elementos são a calma e a visibilidade (Fernsicht). (RIEGL, 1899, p. 2).

\footnotetext{
${ }^{6}$ Cf. WELLBERY, David, 2003, p. 719. A relação entre paisagem e Stimmung foi, segundo Wellbery, investigada, anos depois, em 1913, por Georg Simmel, no ensaio intitulado "A filosofia da paisagem". A Stimmung da paisagem para Simmel é, simultaneamente, atmosfera e tonalidade da alma, na medida em que, para a paisagem, é "[...] essencial a demarcaçáo, o ser-abarcada num horizonte momentâneo ou duradouro; a sua base material ou os seus fragmentos singulares podem, sem mais, surgir como natureza, mas apresentada como "paisagem" exige um ser-para-si talvez óptico, talvez estético, talvez atmosférico (Stimmung), um esquivar-se singular e característico a essa unidade impartível da natureza" [...] A paisagem nasce quando no solo uma ampla dispersão de fenômenos naturais converge para um tipo particular de unidade [...] O suporte mais relevante desta unidade é, sem dúvida, o que se rotula de Stimmung da paisagem, ou disposição anímica. Pois assim como por disposição anímica de um homem entendemos o elemento unitário que coloca constantemente ou só no momento presente a totalidade dos seus conteúdos psíquicos singulares, em si mesmo nada de individual [...] assim também a Stimmung da paisagem penetra todos os seus elementos particulares, sem que, muitas vezes nela se consiga fazer sobressair um só." (SIMMEL, 2009, p. 14)
} 
Desse modo, privilegiando a relação perceptiva, ou seja, a recepção das coisas pelo olho humano, Riegl intercala Nabbild (visão próxima) a Fernbild (visão à distância), ou seja, o tátil e o óptico, oposição que, aliás, está na base da reflexão tanto de Adolf Hildebrando como de Wölfflin,, ${ }^{7}$ reafirmando a metáfora do olhar para caracterizar a arte moderna e nela, de certo modo, a relação de proporção que estava em Kant, na origem da Stimmung musical e nos antigos, seguindo Spitzer. Enquanto "[...] o movimento e a aproximação (Nahsicht) atiram-me na luta pela existência” (RIEGL, 1899, p.2), afirma Riegl, a Stimmung, inversamente, como contraprova (Gegenprobe), é a experiência estética da paisagem na qual, sem a certeza garantida por uma ordem divina, relaçóes físicas são organizadas e apresentadas, através da distância. A Stimmung é, precisamente, a produção de uma unidade formal e a vivência de uma percepção organizada, a qual pode ser traduzida por harmonia ou "atmosfera" e não pela disposição para o reconhecimento de uma bela proporção entre as faculdades. Em Riegl, portanto, o aparecer de um pressentimento de harmonia não tem conteúdo metafísico: a arte não transmite nenhum acesso à veracidade, como numa relação metafísica; ela é, ao contrário, uma medida (Massnahme) criada pelo gesto artístico humano, para ordenar, tolerar a vida ou abrigar-se das contingências; como medida, a Stimmung está em relação estrita com a matéria dada, pois se trata menos, nesse caso, da criação de algo e mais de como algo pode tornar-se uma unidade, constituir uma visibilidade ou um campo no qual a matéria e o sujeito estão em atividade, referindo-se ao espaço e tempo, ou seja, às leis de causalidade. "Essa vivência (Erlebnis) de uma relação formal imanente, quando adquire consciência da certeza da conformidade à lei, é nomeada por Riegl de Stimmung." (WELLBERY, 2003, p.719). De fato, o conceito apresenta-se aqui muito próximo do sentido de coerência formal, desde que seja indicado que essa coerência não é arbitrária ou abstrata, porque Riegl opera com a natureza, isto é, com uma experiência concreta, a experiência da paisagem, de modo que a relação causal é a inscrição do dado sensível numa forma; em termos kantianos, diríamos, grosso modo, que não se trata da experiência real, da coisa em si, porém, da experiência possível, pois a causalidade concerne aos fenômenos, já que só os fenômenos se deixam conhecer por meio do conceito de causalidade. ${ }^{8}$

\footnotetext{
${ }^{7}$ Para Pächt, antes mesmo de Wölfflin, o binômio tátil/óptico já era o fundamento da teoria de Hildebrando, na sua distinção entre Nahbild e Fernbild, oposição que, apesar das diferenças entre os autores, teria influenciado profundamente Riegl. Conferir a apresentação de Otto Pächt à tradução francesa da Gramática histórica das artes plásticas, de Riegl (PÄCHT, 2015, p. 19).

${ }^{8}$ Em Filosofia da paisagem, Simmel aborda esse problema da objetividade ou subjetividade da Stimmung, perguntando se a disposição é uma unidade apercebida, nos termos kantianos, ou uma disposição
} 
É precisamente nesse sentido que a arte moderna, como Stimmung, deriva do próprio conhecimento, "[...] como fruto da árvore do conhecimento", pois hoje sabemos que, diz Riegl (1899, p. 1), “[...] toda obra é atravessada por uma lei da causalidade.” Todavia, a arte não é a ciência, apenas complementa as ciências da natureza: o artista recua, toma distância, pressente algo acima da multiplicidade, produzindo uma obra que ultrapassa o que é meramente útil; a arte, assim, satisfaz o desejo natural do homem de encontrar um consolo, uma ordem e harmonia. Trata-se, no entanto, de um pressentimento efêmero, frisa Riegl (1899, p. 2), “[...] algo táo sutil que na proximidade da agitação da vida, desaparece como um sopro". Por essa razão, a Stimmung manifesta-se não só nos altos montes, mas também no mais profundo mar ou numa praia calma. Definitivamente, a arte moderna não é a reprodução da observação isolada de um fenômeno natural, mas a produção de uma coerência causal, de uma relação entre o próximo e o distante, ou seja, é o "[...] registro óptico de cada impressáo da natureza, que se realiza apenas por seus próprios meios; a arte não é mais proporçóes e beleza de linhas, como na antiguidade clássica, nem elevação espiritual como na Idade Média, mas é agora a estrita observação das leis da causalidade." (RIEGL, 1899, p. 6). A Stimmung, nesse sentido de criação de uma "atmosfera", não se refere tampouco ao insólito, nem à junção ao acaso de elementos díspares, mas àquilo que resulta da reflexão e da experiência criadora de leis da causalidade. Reconhece-se a Stimmung, isto é, essa atmosfera, nas pinturas e gravuras por meio de um grande plano, quando a obra consegue efetuar alguma clareza e nitidez. Eis o sentido da Stimmung, de ver à distância, numa imagem única. ${ }^{9}$ Afastando-se de qualquer ressonância romântica, modulando visão afastada e visão aproximada, Riegl adverte que o artista não busca o infinito, mas a visão afastada a uma certa distância: ele busca um ponto de equilíbrio que possibilite a efetuação de uma unidade óptica, pois a visão, quando é exageradamente afastada, corre o risco de o modelo desaparecer por trás da densa

subjetiva; em outras palavras, se "[...] primeiro vem a nossa representação unitária da coisa ou o sentimento que a acompanha." Sua resposta é clara e busca refutar a tradicional cisão entre a visão e o sentimento, contemplação e afecção; se a Stimmung é um processo humano afetivo, ela só pode ser vivida diante do dado externo, do particular enquanto tal ou, em suas palavras: "[...] a unidade que a paisagem enquanto tal suscita e a disposição anímica que a partir dela em nós retumba e com a qual a envolvemos, são apenas desmembramentos ulteriores de um só e mesmo ato psíquico." (SIMMEL, 2009, p.15-17).

${ }^{9}$ Simmel igualmente corrobora a concepçăo de que a experiência da paisagem é a forma específica de percepção moderna, uma realizaçáo estética possível que decorre da capacidade de contemplar a natureza à distância. No entanto, para ele, a arte é sobretudo um ato espiritual, um comportamento estético ou dinâmica artística que tem uma "legalidade própria". A paisagem, como obra pictórica, permite ao artista "[...] extrair da torrente e da infinidade do mundo imediatamente dado um fragmento, apreendê-lo e formá-lo como uma unidade, que agora encontra em si mesma o seu sentido e intercepta os fios que a ligam ao universo e reata de novo no ponto central que lhe é peculiar." (SIMMEL, 2009, p. 9). 
camada de ar e a retina perceber apenas uma superfície uniforme de luz ou cor, a qual Riegl nomeia de superfície subjetiva. Na aproximação exagerada, por sua vez, os contornos se apagam, as cores se misturam e a oposição entre luz e sombras torna-se incerta. Quer dizer, a forma se perde numa mancha de cor ou de luz (RIEGL, 2014, p.122-125).

O mérito do ensaio sobre a Stimmung de um historiador como Riegl é que ele não é jamais apenas teórico; ao contrário, um dos melhores momentos do ensaio reside na exemplificação. Riegl vê, em primeiro lugar, no século XVII, na pintura holandesa, a adoção do princípio que se baseia exclusivamente na Stimmung. Nessa pintura, o homem não está mais no centro da criação artística, pois foi substituído pela extensão da natureza como um todo, multiplicidade no interior da qual o homem é um mero elo de uma corrente infinita. Como contraexemplo, Riegl, aponta o caso de Rubens, cuja pintura configura a vida em movimento, sempre próxima demais, em convulsôes violentas, o que o impede de estabelecer distâncias e conquistar uma forma harmônica. Em segundo lugar, Riegl indicia, no final do século XIX, nas gravuras de paisagens e arredores, ou pinturas de circunstâncias de Max Liebermann, Storm van s'Gravesande, Böcklin, Max Klinger, elementos de uma "natureza atravessada pelas leis da causalidade", de modo que nelas o circunstancial ilumina a necessidade, compondo uma totalidade perceptível e óptica. Nessas gravuras, assinala ele, a meta do pintor moderno é a apresentação (Darstellung), ao mesmo tempo, do movimento e da imobilidade; as cenas devem figurar a mais completa manifestação da vida orgânica, contudo, sem deixar aparecer o dado externo imediato, de sorte que as paisagens não são parte da natureza, mas recorte e composição, ou seja, poesia da natureza: produtos da criação humana, que efetuam no espectador relaçóes de causalidade e não de ilusão. Assim fazem, ressalta Riegl, os impressionistas quando atribuem às suas figuras contornos ágeis; neles, a paisagem conquista na pintura moderna seu mais distinto lugar.

Por fim, Riegl reconhece, no último parágrafo do ensaio, que vivemos em um tempo espiritual laicizado, haja vista que o espiritual contemporâneo espera mais esclarecimentos das numerosas disciplinas, como a psicofísica, etnologia e ciências sociais, as quais se relacionam com o lado intelectual da natureza humana, do que da fé. A despeito de não elaborar um prognóstico para o futuro, Riegl sugere que a arte contemporânea seguirá essa tendência intelectual, sem suprimir a dissonância caótica da experiência do mundo: a busca por uma harmonia não significa a negaçáo da vida; por essa razão, são 
os artistas aqueles que obtêm os ganhos decisivos desses modernos saberes, ao produzirem alívio e consolo para as gerações atuais que não encontram outras soluçóes no horizonte.

Como balanço final, a Stimmung, em Riegl, não deve ser traduzida por interioridade radical ou por tonalidade da alma, uma vez que, como mostramos, seu campo semântico remete à noção de campo visual e de visibilidade, sendo de fato mais correto verter o termo para atmosfera. Todavia, vê- se com clareza que Riegl de algum modo preserva a noção de proporção, para designar esse movimento artístico de ver à distância, isto é, o sentido antigo do termo ou de um equilíbrio dos modos de percepção em vista da produção de um todo harmônico.

\section{III}

A mesma compreensão da noção de Stimmung como proporção e circunscrição de um campo visual está presente na obra do jovem György Lukács, especialmente em $A$ alma e as formas, de 1910, a qual acaba de ser traduzida pela primeira vez para o português, por Rainer Patriota. Nesses ensaios, Lukács dedica-se às críticas da cultura e da literatura contemporânea, em formato não sistemático, haja vista que a coletânea é marcada pela fragmentação, enunciação de perguntas e articulação de problemas estéticos e filosóficos que não desembocam em saídas e soluçóes. Com efeito, um dos problemas examinados nos vários ensaios é o modus operandi da Stimmung, na arte contemporânea. Enquanto Riegl opera com um conceito histórico estabilizado, de longa duração, Lukács captura na arte contemporânea uma oscilação histórica e semântica do termo. De um lado, o filósofo reconhece, como Riegl, no procedimento da Stimmung uma das marcas da arte contemporânea; de outro, no entanto, vê no deslocamento semântico a dissoluçâo da forma artística que, em crise, substitui os nexos causais e a densidade do sensível, pela pintura lírica dos estados de ânimo (Stimmung) (LUKÁCS, 2015a, p.131).

Com certeza, a dificuldade de traduçáo do termo decorre dessa oscilação do significado nos vários ensaios e mesmo no interior de um mesmo ensaio, já que neles ora a Stimmung é tomada no sentido de Riegl, como circunscrição de um campo, como movimento de aproximação e distanciamento dos órgãos de percepção, isto é, como proporção entre as faculdades para a efetuação de uma forma clara e perfeita, fechada nela mesma e, portanto, autônoma; ora a noção é usada como estado subjetivo, no sentido da interioridade radical de 
Fichte. Para marcar a diferença e referir-se à Stimmung como circunscrição de um campo e princípio de composição, Lukács passa a utilizar o termo em latim Atmosphäre, reservando, a partir daí, o termo Stimmung, no sentido estrito de estado de alma ou tonalidades de alma, para caracterizar o que ele chama de crise da forma, na arte contemporânea.

Isso posto, o que é o estilo atmosférico, ou princípio atmosférico de composição que ele localiza, num arco de longa duração, como em Riegl, no Vita Nuova de Dante, no Werther de Goethe, no Hyperion de Hölderlin, nos idílios de Charles Luis Philippe e nas novelas de Theodor Storm? No plano da literatura, significa a defesa intransigente da forma artística, mas atualizada pela inclusão de novas técnicas, inovaçôes e descobertas formais, dos "novos meios de expressão" que possibilitam a abertura para a mistura de gêneros e aproximaçôes inesperadas, por exemplo, entre o lírico e o épico, através das quais a "[...] exterioridade é conquistada pela interioridade, e o transcendente se faz objeto de uma intuição.” (LUKÁCS, 2015a, p.161). Com isso, por meio do atmosférico, o interior e o exterior permanecem distintos, apesar de entrelaçados mutuamente. Em suas palavras: “[...] o visível não irrompe de dentro das coisas, mas se revela entre as coisas, no brilho de sua superfície e nas vibraçóes de seus contornos; por meio da atmosfera, o inefável pode permanecer não dito.” (LUKÁCS, 2015a, p.162). O atmosférico, enfatiza Lukács, salva as coisas da rigidez dos seus contornos, para lhes dar algo novo: uma firmeza luminosa e um peso flutuante, contudo, a realidade do que é efetivo não é dissolvida, nem desfeita.

Lukács, no entanto, apropria-se criticamente do esquema de Riegl, propondo que, na virada do século XIX para o XX, aquilo que Riegl localizava como uma tendência moderna se tornou não a regra da arte, mas a exceção e uma mera possibilidade, haja vista que a maioria dos artistas e poetas interrompeu a busca pelo ponto de vista, deixando, assim, de perseguir a forma artística, substituindo o rigor formal pela "insubstancialidade e inconstância dos estados da alma”. Com isso, a arte acabou por dissolver a exterioridade em estados de alma (Stimmungen) e "balbucios": o não dito, o que não se "[...] pode dizer se converteu num falatório barulhento e inconveniente, a profundidade em trivialidade e a totalidade de seus instantes brilhantes e nuançados numa monotonia cinzenta e árida.” (LUKÁCS, 2015a, p.162). Desse modo, para Lukács, o atmosférico como visão de conjunto, isto é, como unidade formal é cada vez mais improvável, pois a época, diferentemente do otimismo de Riegl, não é mais favorável a uma forma racional. Isso vale para os gêneros narrativos, 
para o lírico e também para o gênero ensaio: eles se tornaram problemáticos, porque já náo podem selecionar um elemento particular externo, dado de forma imediata, visto que o

[...] olhar agora abrange e articula muitas coisas: [...] o ensaio moderno perdeu o fundo vital, de onde Platão e os místicos tiravam sua força" [...] O que há de problemático na situação se exacerbou até se tornar quase que uma inevitável frivolidade do pensamento e da expressão - e para a maioria dos críticos já se tornou um estado de alma da vida (Lebensstimmung). (LUKÁCS, 2015a, p. 28).

A despeito do diagnóstico da crise na arte, os ensaios de $A$ alma e as formas descrevem, em contrapartida, resistências individuais a essa tendência de dissolver a forma em Stimmung. Cézanne é uma exceçáo, bem como o poeta Stefan George, cujo lirismo resiste a se tornar mera Stimmung. Os que se opóem ao movimento tendencial se tornam estetas, afirma Lukács, pois o esteta é "[...] aquele que nasceu numa época em que o sentimento racional para a forma está morto” (LUKÁCS, 2015a, p.131). Assim, hoje, nessa época não artística, as formas não se desenvolvem mais a partir da vida: ou são abstratas ou inexistentes (LUKÁCS, 2015ª p.174). Se há uma poesia atual, como a de George ou Mallarmé, inevitavelmente ela é obscura e inacessível, austera e rigorosa, porque "[...] ela é resultado de uma reflexão sobre a arte, de uma relação entusiástica com as grandes obras do passado e do estudo de seus segredos." (LUKÁCS, 2015a, p.174).

O impasse que ronda a Stimmung é formulado nos mesmos termos apontados por Riegl, isto é, como um problema de proporção ou de medida. Para Lukács, entretanto, como a relaçáo imediata com a vida se tornou inacessível, bem como a contemplação pura da harmonia do mundo, ou totalidade, como queria Riegl - leitor de Schopenhauer -, o artista precisa construir um padrão de julgamento mediado para "desmascarar tudo que é aparentemente positivo e imediato", apontando na forma criada, a partir de seus "parâmetros" de julgamento, para o que poderia ter "valor, medida e ordem”. Assim, a arte exige cada vez mais distância da vida e, nesse radical distanciamento, o fazer artístico corre o risco de dissolver a forma em tonalidades da alma, o que significa, para Lukács, o fim da forma.

Darei um único exemplo desse paradoxo tal como aparece em $A$ alma e as formas, em dois ensaios complementares sobre os escritores Theodor Storm e Lawrence Sterne. Em Storm, a Stimmung refere-se à unidade formal, suas 
novelas são forma de vida (Lebensform) que apresentam estados de alma vitais (Lebensstimmung); em Lawrence Sterne, em contrapartida, a Stimmung é mera tonalidade de alma. No ensaio intitulado "Burguesia e l'art pour l'art", Lukács sustenta que Storm recusou, no final do século XIX, deliberadamente, a forma do romance, cujo gênero estaria em ascensão, mais próximo da múltipla riqueza da vida e da matéria bruta náo trabalhada, insistindo em permanecer na estrutura da novela, ao modo antigo, seguindo aquilo que Friedrich Schlegel observara, a propósito de Boccaccio: "[...] os estados de alma (Stimmungen) mais profundos e mais subjetivos são expressos apenas indiretamente, apenas pela mediação sensível.” (LUKÁCS, 2015a, p.123). Por essa razão, Storm é, conforme Lukács, o esteta que trabalha com rigor artesanal, cuja obra é um exemplo de arte pela arte; nela, há fusão (Verschmelzen) do exterior com o interior, na qual os "[...] homens experimentam a ação dos acontecimentos externos como internos" (LUKÁCS, 2015a p.101), pois “[...] a disposição do destino (Schicksalsstimmung) reina aqui no interior e no exterior." (LUKÁCS, 2015a p.102). Dessa maneira, o microcosmo que se afirma nessas novelas é a atmosfera (Atmosphäre) do mundo de Storm e náo apenas estados de alma ou sentimentalismo. Em outros termos, a peculiaridade aqui reside no tom atmosférico das narrativas, que, em direta remissão a Riegl, permitem “[...] criar uma distância a partir da qual já não seja visível a dualidade entre externo e interno, entre ato e alma." (LUKÁCS, 2015a, p.124).

Nas novelas de Storm, a atmosfera de fundo (Grundstimmung) peculiar é "[...] o sentimento histórico que se torna um sentimento vital” (LUKÁCS, 2015a, p.118): um sentimento daquilo que desapareceu, porém, que ainda vibra em sua beleza nos velhos móveis de um interior antigo, na recordação sem tristeza, contudo, melancólica desse desaparecimento. A Stimmung desses aposentos, salienta Lukács, recorda os da antiga Holanda, entretanto,

[...] aqui tudo é atmosférico, lírico, sentimental [...] o sentimento histórico desse curso natural das coisas, ao se fazer consciente, coloca-o ao mesmo tempo mais perto e mais longe; a relação com a transitoriedade se torna mais lírica e subjetiva, ao mesmo tempo que se forma à sua volta uma atmosfera (Stimmung) fria de gozo puramente artístico. (LUKÁCS, 2015a, p.118).

Operando com os dois termos, Lukács sugere que, se a Stimmung é o estado de alma ou nostalgia projetada na imagem de objetos antigos, a atmosfera decorre da circunscrição de um determinado campo, curso e conteúdo dos acontecimentos que são envolvidos e integrados em uma 
unidade; ou seja, em Storm, uma totalidade formal é criada, sem que a regra que teria orientado a junção das partes possa ser determinada: "[...] da mistura de aspereza e sentimentalismo surge a atmosfera(Atmosphäre) do mundo de Storm.” (LUKÁCS, 2015a, p.117). Curiosamente, a metáfora utilizada por Lukács para as novelas de Storm é musical: se o sentimentalismo não tem papel decisivo nas narrativas, é porque "[...] seu sentido artístico consiste apenas em acompanhar com uma suave execução em legato os duros acontecimentos em stacatto, dissolvendo as tragédias na atmosfera de um réquiem” (Requiemstimmungen) (LUKÁCS, 2015a, p.118), como uma missa oferecida para o repouso de uma alma.

Lawrence Sterne é examinado num dos mais brilhantes ensaios da coletânea, intitulado "Riqueza, caos e forma: um diálogo sobre Lawrence Sterne”. Para Lukács, Sterne, antes mesmo de Storm, já assume a forma romance, antecipando o contemporâneo, pois nele a Stimmung já é um "princípio" da composição, cujo modus operandi, enfatiza Lukács, pode ser assim resumido:

[...] o autor descreve um fato, surgindo à sua volta uma chusma desordenada de associaçôes suscitadas por ele. Aparece um homem, faz um gesto, diz alguma coisa, ou simplesmente ouvimos seu nome, depois desaparece numa nuvem de imagens, ideias e estados de alma (Stimmungen) gerados com sua aparição. (LUKÁCS, 2015a, p. 196).

Nesse ensaio, a crítica vai além de Sterne, atingindo a Weltanschaaung da qual ele deriva, isto é, do romantismo e especificamente de Fichte, pela exacerbação da subjetividade e abandono da noção de proporçáo que estaria em Kant. Para Lukács, neokantiano, a obra de Sterne mobiliza apenas parcialmente as faculdades, inibindo a possibilidade do jogo estético, de sorte que a capacidade formal é pouco ativa; por essa razão, "Sterne não tem tato e sensibilidade para o verdadeiramente importante", a vivência surge pelo mero gosto pela vivência e, citando Nietzsche, Lukács (2015a, p. 206) proclama: "[...] nunca observar apenas por observar." Em Sterne, a vida aparece apenas na sua desordem caótica, de forma bruta, como dado empírico imutável; por isso, frisa Lukács, as obras de Sterne são informes, inorgânicas, fragmentadas, inacabadas e, por isso, prolongáveis ao infinito; nelas, não há escolhas, nem valores, nem ética. Contra essa tendência, Lukács (2015a, p. 213) afirma:

[...] ordem e caos provêm de uma mesma raiz primordial, por isso uma alma só pode ser completa e assim rica lá onde existem com igual intensidade 
caos e conformidade à lei, vida e abstração, homem e destino, estados de alma Stimmungen e ética.

Contra os românticos, o jovem Lukács é incisivo: não há forma infinita, toda forma é delimitação, escolha, ordenação da multiplicidade; sem forma, não há beleza.

Em $A$ alma e as formas, Lukács sugere a dimensão trágica da consolidação da Stimmung na arte contemporânea: conhecemos concretamente cada flor e mil pequenas relaçóes, admite ele, mas "[...] as paisagens de nossa alma não existem mais em parte alguma” (LUKÁCS, 2015a, p. 139). Diante da mais absoluta proximidade reside a mais terrível obscuridade e, na compreensão de tudo, a mais absoluta incompreensibilidade. Em um ensaio de 1910, intitulado "Cultura Estética" (Ästhetische Kultur), Lukács, em chave crítica, assinala que a Stimmung como tonalidade da alma e não mais como atmosfera consolidou-se como o ponto central da cultura contemporânea. De fato, como previa Riegl, "[...] a atividade espiritual laicizada se estendeu à totalidade da vida; essa vida, no entanto, reduziu-se à sucessão incessante de estados de ânimo." (LUKÁCS, 2015b, p.187). Não há mais permanência, durabilidade, nem unidade: nada vai além do meramente individual, não há mais como tocar o centro da vida. $\mathrm{Na}$ arte, a vida se tornou tonalidade de alma (Stimmung), isto é, a redução da atividade espiritual à interioridade e não a aproximação entre arte e vida, como queriam alguns vanguardistas. Com efeito, a interioridade significa submissão e adaptaçáo passiva às coisas, dada a incapacidade de o artista penetrar no coração das coisas; passividade que é, no limite, incapacidade de criar e de atuar, a qual Lukács nomeia de diletantismo ou de hedonismo diletante, por meio do qual se criam castelos evanescentes ou um conjunto agradável de superfícies (LUKÁCS, 2015b, p.188-189).

O jovem Lukács, diferente do maduro, reconhece que é impossível escapar dessa tendência e que os melhores artistas são aqueles que, ironicamente, aprofundam essa via da interiorizaçáo, explorando os paradoxos do Eu até a exacerbação dos seus próprios limites. ${ }^{10}$ Hofmannsthal certamente é um deles, ao captar também essa transição, na famosa Carta a Lord Chandlos, de 1902,

\footnotetext{
${ }^{10}$ Márkus (1977, p. 106), comentando o ensaio "Cultura estética", assinala que, no jovem Lukács, diante do mundo da convençấo e da superficialidade, só há duas possibilidades ao ser: emergir no mundo da convençáo e perder a personalidade ou escapar do peso da necessidade exterior irracional pela interioridade, o que, nesse caso, significa abrir-se aos estados de ânimo contingentes (Stimmungen) e também sacrificar a identidade.
} 
na qual o poeta anuncia desistir da poesia, por não se considerar mais capaz de criar formas, pois perdera o "conhecimento da forma". Termino esta série com a descrição desse mal-estar: angustiado e doente, confessa o poeta,

[...] tudo foge de mim, experimento um mal estar inexplicável, [...] meu espírito obrigava-me a ver tudo o que aparecia como algo terrivelmente próximo. Uma vez vi numa lente de aumento um pedaço da pele de meu dedo mindinho assemelhando-se a um campo rachado de sulcos e crateras, assim via agora os homens e as açóes. Não conseguia mais apreendê-los com o olhar simplificado do hábito. Tudo desintegrava-se em pedaços, pedaços e mais pedaços e nada mais conseguia ser abarcado por um conceito. As palavras isoladas inundavam-me; aglutinavam-se em olhos que me fitavam e para os quais via-me obrigado também a fitar: turbilhoes são as palavras. Sentia vertigem ao olhar para elas, girando sem parar e através das quais só se consegue chegar no vazio. (HOFMANNSTHAL, 2010, p. 29).

SILVA, Arlenice Almeida da. Notions of Stimmung (mood) in a historical series: between disposition and atmosphere. Trans/Form/Ação, Marília, v. 39, p. 53-74, 2016. Edição Especial.

\begin{abstract}
The relationship between art and philosophy is examined based on the notion of Stimmung (mood), which appears in eighteenth-century music theory as a proportional relationship between tones or instruments; it was then incorporated into aesthetics at the end of the century in the works of Kant and Fichte. In Kant's works, Stimmung refers to the capacity of the faculties of knowledge for knowledge in general, that is, as a presupposition of aesthetic presentation through which the notion of proportion between the faculties is preserved. In his On the Spirit and the Letter in Philosophy, Fichte points out that the aesthetic disposition is the mode by which the aesthetic impulse acts out, connected freely and directly to the faculty of imagination and to the activity of creation. This aesthetic tradition is revisited by the historian Alois Riegl in 1899 in the essay Die Stimmung als Inhalt der moderne Kunst (Mood as the Subject Matter of Modern Art), where the concept of Stimmung is first presented from historical perspective as content of modern art in the sense of atmosphere, i.e., the experience of a relationship by which awareness, in accordance with immanent law, acquires certainty. A similar review was done by the young philosopher György Lukács in 1910 in Soul and Form, where the author conceptualizes the differences in meaning between the notions of Stimmung and Atmosphäre (atmosphere).
\end{abstract}

KEYWORDS: Stimmung. Kant. Fichte. Riegl. Lukács. 


\section{REFERÊNCIAS}

CECCHINATO, G. Fichte und das problem einer asthetik. Würzburg: Ergon, 2009.

DAMISCH, H. Le text mis à nu. In: RIEGL, A. Questions de style: fondements d'une histoire de l'ornamentation. Tradução de Henri-Alexis Baatsch e Francoise Rolland. Paris: Hazan, 2002. p. 9-23.

FICHTE, J. G. Sobre o espirito e a letra na filosofia. Tradução de Ulisses Razzante Vaccari. São Paulo: Humanitas; Imprensa Oficial, 2014.

GUMBRECHT, H. U. Atmosfera, ambiência, Stimmung: sobre um potencial oculto da literatura. Rio de Janeiro: Contraponto, 2014.

HOFMANNSTHAL, H. Von. Uma carta. Viso: Cadernos de Estética Aplicada, Rio de Janeiro, n. 8, p. 24-34, jan/jun. 2010.

KANT, I. Crítica da faculdade do juizo. Tradução de Valério Rohden e António Marques. Rio de Janeiro: Forense Universitária, 1993.

LUKÁCS, G. Die seele und die formen: Essays. Berlim: Luchterhand, 1971.

A alma e as formas: ensaios. Tradução de Rainer Patriota. Belo Horizonte: Autêntica, 2015a.

. Cultura estética. In: Acerca de La pobreza de espiritu y otros escritos de juventud. Tradução de Miguel Vedda. Buenos Aires: Gorla, 2015b.

MÁRKUS, G. Die Seele und das leben. Der junge Lukács und das problem der 'Kultur'. In: Die seele und das leben. Baden-Baden: Suhrkamp, 1977. p. 99-130.

PÄCHT, O. Aloïs Riegl. In: RIEGL, A. Grammaire historique des arts plastiques. Volonté artistique et vision du monde. Tradução de Eliane Kaufholz. Paris: Hazan, 2015.

RIEGL, A. Die Stimmung als inhalt der modernen Kunst. In: ROSENNAUER, A. (Org.). Graphische künste, XXII, 1899. S 47 ff.

. Gesammelte aufsätze. Viena: Facultas, 1996.

- Questions de style: fndements d'une histoire de l'ornamentation. Traduçáo de Henri-Alexis Baatsch e Francoise Rolland. Paris: Hazan, 2002.

Grammaire historique des arts plastiques: volonté artistique et vision du monde. Tradução de Eliane Kaufholz. Paris: Hazan, 2015.

SIMMEL, G. A Filosofia da paisagem. Tradução de Artur Morão. Covilhã: LusoSofia, 2009.

SPITZER, L. Classical and christian ideas of word harmony: prolegomena to an interpretation of the word "Stimmung". Baltimore: Johns Hopkins, 1963.

WELLBERY, D. Stimmung. In: BARCK, K. et al. (Org.). Historiches Wörterbuch ästhetischer Grundbegriffe. Stuttgart; Weimar: Metzler, 2003. V. 5. p. 704-733. 
WELSH, C. 1800-1900 - Ästhetische und psychische Stimmungen im wandel dualistischer modelle. In: DAUSS, M. Leib/Seele-Geist/Buchstabe: dualismen in der Ästhetik und den Künsten. Würzburg: Königshausen \&Neumann, 2009. p. 269-292.

Recebido / Received: 10/06/2016

Aprovado / Approved: 11/08/2016 
SILVA, A.A. 